\title{
The evolving group: towards a prescriptive theory of intentional group development
}

\section{Article}

Accepted Version

Akrivou, K., Boyatzis, R.E. and McLeod, P.L. (2006) The evolving group: towards a prescriptive theory of intentional group development. Journal of Management Development, 25 (7). pp. 689-706. ISSN 0262-1711 doi:

https://doi.org/10.1108/02621710610678490 (special issue 'Intentional change from a complexity perspective') Available at https://centaur.reading.ac.uk/23945/

It is advisable to refer to the publisher's version if you intend to cite from the work. See Guidance on citing.

To link to this article DOI: http://dx.doi.org/10.1108/02621710610678490

Publisher: Emerald

All outputs in CentAUR are protected by Intellectual Property Rights law, including copyright law. Copyright and IPR is retained by the creators or other copyright holders. Terms and conditions for use of this material are defined in the End User Agreement.

\section{www.reading.ac.uk/centaur}

\section{CentAUR}


Central Archive at the University of Reading

Reading's research outputs online 
The Evolving Group: Towards a Prescriptive Theory of Intentional Group Development

Kleio Akrivou, Richard. E. Boyatzis, Poppy L. McLeod

Word Count:

2006, Journal of Management Development, V.25, issue 7 


\begin{tabular}{|c|c|}
\hline Category: & Conceptual Paper \\
\hline Purpose of this paper & $\begin{array}{l}\text { To provide a theoretical framework for understanding and } \\
\text { formulating team itentional change }\end{array}$ \\
\hline Design/Methodology/Approach & $\begin{array}{l}\text { Based on a critical review of existing theories of group } \\
\text { development, gaps in the literature regarding how teams } \\
\text { can and should develop, especially when the change is } \\
\text { intentional and has a desired direction, as examined. A set } \\
\text { of propositions are offered to address these aspects of } \\
\text { group development that have been neglected by the } \\
\text { literature. }\end{array}$ \\
\hline $\begin{array}{l}\text { Findings / Analyses / } \\
\text { Discussion }\end{array}$ & $\begin{array}{l}\text { A systematic and critical discussion of the core literature on } \\
\text { group development showed: (1) the complex and } \\
\text { discontinuous nature of change in groups was neglected, } \\
\text { because the group was not treated as a complex system; (2) } \\
\text { the literature has not dealt with group development } \\
\text { processes when the change process is intentional It has } \\
\text { been descriptive of what occurs), nor has it examined } \\
\text { which are key drivers of group change; (3) existing } \\
\text { literature on group development have predominantly seen } \\
\text { negative emotion as catalytic to group development, and } \\
\text { they have ignored the role of positive emotion. Therefore, } \\
\text { drawing on positive psychology, complexity theory, small } \\
\text { group research literatures, and Boyatzis' Intentional } \\
\text { Change Theory, a prescriptive theoretical frameworkfor } \\
\text { explaining intentional group change and development_is } \\
\text { offer discussed. }\end{array}$ \\
\hline What is original value of paper & $\begin{array}{l}\text { A prescriptive model or theoretical framework with a set of } \\
\text { hypotheses are proposed that explain intentional, and }\end{array}$ \\
\hline
\end{tabular}




\begin{tabular}{|l|l|}
\hline & positive group development processes \\
\hline Key Words: & $\begin{array}{l}\text { Intentional group development, Intentional change, group } \\
\text { development, group processes, group, leadership }\end{array}$ \\
\hline
\end{tabular}




\section{Introduction}

Existing theories of group development have not treated the group as a complex system, thus they did not pay enough attention to certain aspects of the group development process, such as the complex and discontinuous nature of change in groups. Secondly, the literature has not examined group development processes when the change process is intentional. Accordingly, they have not examined drivers of group change. Thirdly, existing literature on group development have predominantly seen negative emotion as catalytic to group development, and they have ignored the role of positive emotion.

To address the above, the authors review existing theories of group development in social psychology, management and organizational literatures, and summarize underlying themes, contribution, and links. Gaps in this knowledge create the opportunity for the development of new models of group development are discussed. The authors propose that to explain sustainable group development and the identity transformation that can take place on the basis of: (a) complexity and multi-fractal interaction; (b) intentionality; and (c) positive emotion.

Drawing on positive psychology (Aspinwall et al., 2003; Cameron et al., 2003; Chang, 2001; Seligman; 1991; Snyder, 2002, 2000, 1994b), complexity theory (Andriani \& McKelvey, 2005; Boyatzis, 2004) and small group research literatures (Arrow et al., 2000, 2005; Chang et al, 2003; McLeod, 2005; Von Cranach, 1996;) and based on Boyatzis' Intentional Change Theory (ICT) (Boyatzis, 2001, earlier in this issue) a prescriptive theoretical framework for intentional group development is proposed. The authors propose and discuss a set of propositions, and argue that they address some of the gaps of previous literature regarding intentional group change and development.

Within this framework, the authors propose and discuss a series of propositions regarding intentional group development. To summarize the main points of these 
propositions: (a) intentionality and shared ideals are the drivers of change and group transformation; (b) a series of discontinuous discoveries leads the group and its members in various iterations of change; (c) each iteration is bound in the Positive Emotional Attractor. Positive emotion thus, becomes critical for intentional group development. It is activated by the group's drawing its primary motivation from visions of its ideal, (d) in each iteration of ICT at the group level, alternating activation of positive and negative emotional attractors (Boyatzis, earlier in this issue) is also critical for the group's intentional change, when each iteration of intentional change is rooted in positive emotion; Each iteration of ICT expands the group's conscious awareness, or mindfulness, the salience, as well as the coherence of this ideal (Boyatzis and Akrivou, earlier in this issue). Transformation at the group level can be catalyzed and facilitated by formal or informal positive emotional leadership in the group.

Finally, implications for research and organizational practice in the areas of group motivation, group development and group process, are offered, if one takes into account the proposed dimensions and framework of intentional change and development.

\section{Existing Theories on Group Development}

Literature shows a variety of approaches to group development. Thorough analytical reviews of group development literature (Arrow et al., 2005; McLeod, 2005; Chang et al., 2003) have proposed two bases of all existing group development models: (1) the psychodynamic perspective of group development; and (2) the temporal perspective of group development. With different assumptions on the nature and drivers of change, as well as the antecedent theoretical traditions in social sciences, each model leads to one or more of the existing models of group development. Tuckman (1965) offered an alternative. He claimed the setting in which the group is formed and operates (e.g., therapy group, training group, natural group or laboratory group) and the nature of the group behavior (e.g., task oriented or 
process, intrapersonal oriented action) can be used to classify all group models (Bales, 1953, 1951, 1950; Deutsch, 1971; Tuckman, 1965).

Two paradigms or schools of thought regarding group development emerge from these reviews. One paradigm sees change as a systematic process over time (Arrow et al., 2005). In other words, group development results from incremental addition of small and smooth mutations. In this paradigm, the therapy, training or laboratory group settings are overrepresented. With its base in the major psychoanalytic traditions of last century the issues of conflict at the intra-personal level which is projected at the group level (Deutch, 1971), anxiety, guilt and repressed negative emotions (Freud, 1936; 1959) are critical variables used to understand group development. McLeod (2005) defined this as "an approach to the study of group behavior that focuses on the relationship between the emotional, non-conscious processes and the conscious rational processes in human interaction."

Linear/progressive models see patterns of group development as an unvarying sequence of stages and activities and has focused in discovering the content and order of these stages (Gersick, 1988; Poole, 1983). This second paradigm sees change as non smooth and non-gradual trajectory towards uniquely defined and pre-set ends (Gersick, 1991, 1988), but occurring through the alteration of inertial change and revolution in the behaviors and themes through group members approach their work.

The first paradigm, which we will call the "psychodynamic, or progressive change paradigm" has heavily been influenced by natural evolution theories. The second paradigm, which we will call "the punctuated equilibrium paradigm" is influenced by contemporary evolutionary biology and natural history theories (Gersick, 1991). Additionally, this second paradigm was initially described by its authors, as inspired by revolutionary theories (Gersick, 1991). 


\section{The Psychodynamic, or Progressive Change Paradigm}

Within this paradigm, the literature shows three streams of thought. The progressive, or linear additive models (Bennis and Sheppard, 1956; Mills, 1964) are based on the idea that the group moves onward and upward to its implicit goal and is described as moving toward the resolution of distinct issues, often of opposing nature. For example in Bennis' and Shepard's model the issues of dependence vs. interdependence as a key conflict to be resolved. Originating from the period of Enlightenment in Europe, individual development theories were replicated in the models of development of the group as a whole (Hartman \& Gibbard, 1973; Gibbard \& Hartman, 1973).

The recursive models (Tuckman, 1965; Bion, 1961; Shutz, 1958) are very similar to all the main ideas of the linear-progressive model of group development. Its main difference is that although the linear model assumes that the group life and activity moves towards a peak of effectiveness and then continues to function at this level, the life cycle modes add a terminal phase of decline and "death of the group". It places the period of maximum productivity near but not at the end (Hartman \& Gibbard, 1973; Gibbard \& Hartman, 1973c).

The morphing models are based on a time based exchange of forces and issues and costant emergence). Most representative are the models offered by Bales (Bales, 1953; 1951, a,b,c; 1950) and Slater (in Tuckman, 1965) who was a student of Bales. These models postulate that there are boundary issues in small group life which are actually based on conflicts and discomforts deeply rooted to the human condition. Therefore they cannot be simply overcome, or achieved and then disappear. Although these models show a progressive mode towards resolving or overcoming basic dysfunctions, the dynamic issue of equilibrium can never be attained (Hartman \& Gibbard, 1973; Gibbard \& Hartman, 1973c). 
Bales (Bales, 1953; Bales \& Strodbeck, 1951) was the first to offer a major theoretical contribution on small group development. He worked with laboratory groups, using the Bales Interaction Process Analysis (IPA, Bales, 1950). He found that problems of orientation (finding out about the task, what has to be done and how it should be best accomplished) dominate the initial phase in the life of leaderless groups, followed by a phase of evaluation. In the IPA, evaluation is reflected by codable behaviors around the exchange of opinions and feedback among group members. The exchange of opinion regards task related exchange, but also self related exchange, depending on the nature and the formal objective of the group.

Bach (1954), among the pioneers in therapy group research, proposed the initial situation testing as the first stage of group development of therapy groups, accompanied by leader dependence behaviors. Then he proposed a stage during which the salient phenomenon is the development of intra-group consciousness. During this stage, establishment and maintenance of group boundaries is a key issue in the life of the group (Tuckman, 1965). His third and final proposed stage was called the work group, a construct used also some years later by Bion. This was a stage predominantly characterized by task interaction among group members (in therapy groups, task was focus on therapy itself) and minimization of emotional reactions interfering with task behaviors.

Bennis and Shepard (1956), used their observations and research of training groups to propose a model of group development characterized by two major phases, with a number of sub-phases within each phase. Based on this model, the initial phase is an authority one, with key issue the issue of individual dependence, while the second phase is an interpersonal one, with key theme the issue of interdependence. The group can resolve its internal conflicts and perform only if the individual can resolve its internal conflicts in regards to his/her boundaries in the group. This model sees two major areas to be dominating individual internal conflicts in groups: dependency and interdependency. The model is progressive and 
linear in the sense that the group is portrayed moving onwards and upwards, towards the resolution of these two distinct issues, with dependence issues met earlier in the developmental sequence and interdependence subsequently.

Schutz (1958) has worked on the developmental sequence in natural and laboratory groups. He proposed a pendulum of group development with three stages continually cycling over time. The initial phase of group development is proposed to be related to problems of inclusion. Members are conflicted upon the dilemma "to join, or not to join" the group. In Schutz's theory the behavior of members is individually centered and the group concern is boundary issues (Tuckman, 1965). He proposes a second stage, where the predominant theme is around control, with main sub-theme a leadership struggle with competition among all individual members of the group. Finally Schutz proposed a third stage, which is characterized by issues of affection, intimacy and resolution of intimacy problems of previous phases, and emotional integration among the members of the group. His last stage is characterized by the reversal of the previous patterns, from inclusion-control-affection to affection-control-inclusion (Hartman \& Gibbard, 1973).

Bion (1961) said that abnormal behavior in groups is dominated by certain basic assumptions, which cause strong emotional interference which hinders the accomplishment of the task of the group (work group). He proposed four stages of group development where one basic assumption is the dominant. An initial stage which is based in the basic assumption of dependency is followed by a subsequent phase which is characterizes as a fight and flight period. This phase is followed by a third one, based on the basic assumption of pairing. During this phase there is cohesion in different dyads in the group. Sometimes this pairing can oppose to the rest of the group. The final stage offered by Bion is the one of the work group, during which the group serves its main task and function - in the case of therapy groups the task becomes therapy itself. This stage is different from the previous three basic 
assumptions of dependency, fight and flight and pairing in the sense that there is a predominance of task related behaviors by the members and a minimum of emotional interference.

Mills (1964), based on qualitative research proposes a life cycle model with five stages of group development: (1) the encounter; (2) testing boundaries; (3) negotiating an indigenous normative system; (4) production; and (5) separation. The first two are in Tuckman's terms the forming with elements of storming, the third is Tuckman's norming stage, while the fourth his performing stage (Hartman and Gibbard, 1973)

Tuckman (1965), after reviewing and comparing the literature has proposed a linearprogressive conceptual model of group development, which was serving also functions of integrating and organizing the antecedent research on groups in one model. In this model four stages of group development are proposed. In the Forming stage, testing becomes the key concern of groups. At the interpersonal level, we see the establishment of dependency relationships with leader(s), other members of the group or pre-existing standards and norms. In the Storming stage, resistance to both group influence and task requirement is shown. During this phase conflict, polarization around interpersonal issue and negative emotional responding to the task requirements. In the Norming stage, resistance and conflict are overcome and together with the development of cohesiveness, new standards, norms and new roles emerge for the group member. During this stage, intimate personal opinions are expressed. In the Performing stage, interpersonal structure becomes the tool through which group energy is channeled into the task with results enhancing group performance.

Slater (1966) developed a pendular complex model of group development, emphasizing the role of revolt in the establishment of solidarity and cohesion at the group level as well as involvement in shared task activity. He sees the wish/fear dilemma, resulting 
from individuals wish to merge with the group yet at the same time not lose their autonomy, as driving a boundary evolution (Hartman \& Gibbard, 1973).

Mann (1967, 1966) in his life cycle model with therapy (self-analytic) groups, based on observation of self-analytic groups agrees with the previous literature. He proposed an initial stage of testing to define the tolerance of the group itself and the therapist-leader, then a stage of resistance with major phenomena centered around "working through of hostility", followed by "working through of anxieties". During the latter, some major psychological issues of the hostility stage are slowed down and attenuated. Mann sees the next stage as one characterized by personal mutual exploration and exchange when discussion of personal problems in depth takes place and negative emotionality is reduced. Then he offers a final stage of personal, mutual synthesis. Mann gave a lot of attention to this terminal phase of self-analytic groups and his research contributed two distinct terminal sub-phases, the "separation" and the "terminal review" in his life cycle model of group development.

\section{The Punctuated Equilibrium Paradigm}

This paradigm was perceived until recently as opposing and contradicting to the linear progressive paradigm of group development (Chang et al. 2003). It is stressing the notion of timing or mechanics of how a group moves from one stage to a subsequent one, or how groups go about adapting stages into time limits (Gersick, 1988,b; Hare, 1976; McGrath, 1986; Poole, 1983b;Tuckman, 1965;).

Task forces in different settings (i.e., task forces are natural groups, operating within specific and often limited time periods) develop until the completion of their task. Gersick found that such teams did not fit the traditional paradigm (Gersick, 1988, a, b). Although there was variation in the way these teams developed, Gersick showed that development phases were marked by a "punctuated equilibrium". They were characterized by different 
periods of inertia. Groups exhibited a somewhat unique approach to its task as they commenced and remained in this condition over time. This phase was interrupted precisely halfway through the group's overall duration. It was described as a midpoint transition of big, revolutionary changes in the group's overall structures and processes in order to achieve its task. Every group then underwent a fundamental change in its initial conditions adopting new perspectives on their work and structure and remaining in this condition over time. This second phase of inertial activity was interrupted one last time, which in all groups occurred just before their deadlines, initiating a final stage of intensive activity to complete their mission and task (phase 3). The findings with natural groups were also supported during replication of research in laboratory, experimental settings. In her model, the "phase shifts" were similar to the same concepts in physics and material sciences. They are moments of discontinuous, often non-linear change best understood through complexity theory.

\section{Underlying Patterns, Assumptions, and Gaps}

Early studies comparing the two models showed that theories from the progressive and the punctuated equilibrium models complement each other (Arrow, 1997; Lim et al., 1994; Seers et al, 1997; in Chang et al., 2003). This offered the possibility that they could be integrated. It appeared that groups go through both punctuated equilibrium (i.e., group's awareness of time and pace as well as changes in the task) and linear progressive development (i.e., changes in the socio-emotional aspects of the group and how these impact task behavior). In addition, based on Wollin (1999), it appeared that the punctuated equilibrium model explained development in groups at a more fundamental and macro level, while the linear progressive model explained developmental at a micro and incremental level. Thus, depending on the temporal dimension and the lens of observation, micro level phenomena are taking place within the larger macro level phenomena of development. 
A major breakthrough was offered by Arrow et al. (2005). In their review of existing models of group development, the authors offered a typology of group development theories using three: change, stability and continuity. They defined change as "an alteration in the nature of group interaction or performance, in the state of the group as a whole, or a second order change in the patterning of group process". They explained stability processes as ones "dampening fluctuations, maintaining groups in their current state, or restoring groups to a prior equilibrium, countering the impact of external or internal forces for change or transformation". They defined continuity, as a process "occurring in groups that experience change while maintaining and reenacting consistent patterns and structure". They postulated that the nature of change in group development theories is seen as systematic change over time. Additionally, these authors proposed that group development models differed on two dimensions: (1) whether the primary source of continuity was internal or external forces; and (2) the extent to which forces of change and stability were internal or external to the group. In addition, Arrow et al. saw that, in opposition to all existing models which treat change as a systematic process over time, the emerging novel perspective on group development comes from the scholars "treating groups as complex systems and developing theory and research methods commensurate with this complexity" (Arrow et al., 2005).

Once complexity theory is embraced as a way to understand change in human groups many inconsistencies in existing theories dissolve. The implications of complexity perspectives in the conceptualization of change and development is briefly described in more detail in Boyatzis (earlier in this issue). Complexity theory allows integration of research from positive psychology (Aspinwall, ; Aspinwall et al., 2003 ; Cameron et al., 2003; Chang et al., 2003; Scheier \& Carver, 1997 ; Seligman, 1991 ; Snyder, 2002, 2000, 2996, 1994;) and emotions (Fredrickson, 2001; Fredrickson et al., 2002, 2000; Tugade et al., 2004). These fields add detail toward the development of inspired, positive theoretical models of group 
development. Therefore, we would like to propose the following propositions regarding the nature and process of group development.

Past models describe change that is not necessarily intentional nor conscious. They describe change from an evolutionary point of view, which happens irrespective of the agents' own will and often without their awareness. In addition, these models have been descriptive and normative, suggesting a degree of determinism. They start with assumptions that groups change over time and that these changes follow a predictable pattern. They differ with respect to the nature and pattern of change. But they all assume an upward evolutionary movement, towards higher states of maturity and capability over time. None of these models have been prescriptive and propose the way to improve and achieve effectiveness in groups. In this article we are going to offer a prescriptive model of group development, proposing that, if we want assume change as an upward movement, then the nature of change should be seen as an intentional and conscious process.

Proposition 1: Desired change in groups can be intentional and will be more effective and efficient when it is conscious and intentional.

In existing models of group development, negative emotionality was an essential, explicit and/or subtle underlying theme. Negative emotion was seen as a catalyst for change in the group. In the linear and progressive paradigms, this is described as the predominance of individual intra-psychic conflicts, causing strong emotion at the group level. Strong negative emotion at the group level is seen as hindering the group task, or the formation of a shared identity. At the same time, negative emotionality and resistance are seen as catalysts for group development, therefore dealing with them has a cathartic nature. It appears that the more psychologically driven small group literature in the linear / progressive paradigm was never able to move away from its antecedent problem oriented approach (Davies et al, 1988, in Manson, 1993) and the impact of Freudian psychology (Hartman, 1970). Also, in this 
paradigm, the therapy group had been overrepresented in the literature and research, while settings like the natural or the laboratory group settings had been underrepresented (Tuckman, 1965).

- Even in the punctuated equilibrium model, negative emotion had a central but subtle role. In this model, negative emotionality was seen as related to time angst in groups. In Gersick's model, reaching the midpoint in group's life is often associated with a strong negative emotion that breaks routine structures and patterns. Gersick (1998, 1999, 1990, 1991) said that optimism arises following this radical change. In both paradigms, there is no positive internal driver of group development. The psychodynamic model stresses the role of intra-psychic anxieties projected at the group level, resulting in defensive and reactionary processes in initial stages of group development and sees that "catharsis" naturally follows projected inter-personal suffering. The punctuated equilibrium model sees the impact of time and pacing as causing reactive patterns, which result in revolutionary changes in the collective behavioral patterns at the group level.

Proposition 2: Positive emotion creates intrinsic motivation for intentional group development.

We believe that a group's shared vision of what they want to be and do as a group is the driver of intentional change. At the group level of ICT, the emergence of a shared ideal starts intentional change. This takes into account both a psychological and a sociological definition of the group (Manson, 1993). The group emerges in the consciousness of individual members when it becomes salient within each member's psyche. Group interaction is then able to stimulate individual, intrinsic motivation. From a sociological perspective, we agree with Ridgeway's proposition that a group "must share an identity, or sense of purpose," and this is how it influences its members to see the group identity as more salient than personal identities (in Manson, 1993). 
Proposition 3: When a shared ideal, or group vision emerges, intentional change theory predicts sustainable, group development.

\section{Towards a Prescriptive Theory of Intentional Group Development}

ICT offers a framework treating group development as a complex system. This framework proposes that group development is often non linear. "The nature of nonlinear interaction means that ... despite the fundamental unpredictability at the level of local interaction, the behavior of the collective exhibits regularities that are much simpler than the myriad interactions from which this regular behavior emerges" (Arrow et al., 2005).

ICT (Boyatzis, 2001, earlier in this issue) treats group development as a complex and often discontinuous change process that parallels and interacts with change at other levels of social organization. In this application to group development, ICT describes a series of discoveries or emergent stages that seem catastrophic.

Ass a model of intentional change and development in groups, it provides the means for improving group development by increasing self-awareness within the group. The motivational force for salient and sustainable change comes from the group members desires to evolve in a desired direction of the group level of the Ideal Self (Boyatzis, earlier in this issue; Goleman, Boyatzis \& McKee, 2002). Boyatzis and Akrivou proposed a model of the Ideal Self at the individual level. They claimed the Ideal Self is related to three main psychological processes: (a) hope, the emotional driver; (b) an image of the desired future, the content of change; and (c) core identity, their personal context. At the group level, the Ideal Self could be described as a Shared Ideal, or vision, which would be derived through: (1) emergent awareness of a shared hope; (2) collective imagery regarding the ideal purpose and functioning of the group; and (3) realization and articulation of a core identity of the 
group. As explained above, deep positive emotion underlies the processes linked to the ideal self, and its equivalent in the group level, the shared ideal, or vision. Hopes, dreams and possibilities make up the concept of the ideal at the group level and become the motivational driver for change and development across time.

Although the positive emotions, a central element in the Positive Emotional Attractor (PEA) (Boyatzis, earlier in this issue) becomes the pull towards development, in ICT negative emotion has a functional role. Negative emotion, linked to the Real Self becomes the pull towards a Negative Emotional Attractor (NEA) (Boyatzis, earlier in this issue). At the group level, the Negative Emotional Attractor and the Real Self are translated to the existing norms and underlying patterns of behavior that often result in groups being stuck in paradoxical states in group life (Smith \& Berg, 1987). It would also manifest itself as the socio emotional processes related to boundary issues either between the group and other groups, known in social identity theory as inter-group relationships (Hogg and Tindale, 2003), or the internal boundary (i.e., the boundary between the individual and the group, resulting in various intra-group processes).

\section{The Emerging Group}

ICT is a recursive model. In group development, we believe it is better described as a spiral. Intentional Change emerges through a series of five discoveries, in multiple iterations during the group's life. Although each iteration is characterized by a similar cycle of discovery, over time, there is a shift to distinct patterns in a way which makes group development appear unique for each group.

Proposition 4: Intentional group development is a recursive iteration through the five phases of Intentional Change Theory, but at progressively greater depth and positive impact on the group. It is probably best portrayed as a spiraling through the ICT phases. 
ICT iterations have a transformative effect for the group. The group enters each subsequent iteration as a completely new start, and a novel experience. Over time, the group experiences a broader and deeper scope of intentional change, as well a greater degree of group identification. Multiple iterations lead the group to increasing group consciousness, or self-awareness, increased salience, or intensity, and increased coherence, or holistic and integrated sense of the group's core identity, vision and purpose. The way the various ICT iterations transform the group identity and enlarge the scope of intentional change are shown in Figure 1. Also, the number, form and content of ICT iterations can vary highly among groups, depending on their composition, degree of diversity and members identity complexity, memberships in other groups, structure, task, life span, past history, surrounding systems, leadership model in the group, nature and degree of interrelationships of roles, etc.

insert Figure 1 about here

It is difficult to predict the number of iterations needed to fundamentally transform the group. The movement from one stage of ICT to the next is a smooth, continuous transition is the group is highly self-aware of its own processes. But in most groups, development involves hitting successive tipping points in the issues central to each stage. The tipping point, in this sense, is the marker of a phase shift.

A required feature of multi-level, complex systems is some form of interaction among the levels. Each iteration of ICT involves multi-fractal interaction. Group development involves mainly interaction among four fractals: (1) the intra-individual; (2) dyads or coalitions; (3) the group; and (4) the supra-system in which the group is embedded (i.e. the organization, or community, or society). In early iterations, only some of these fractals interact, while in later iterations the interaction among fractals is more complex and dynamic. 
Proposition 5: Intentional group development involves interaction with intentional change at other levels of human/social organization (i.e., individual, dyad, organization, country, global).

Leaders help move a group into each of these phase shifts. In this manner, they also help a group to enter a new cycle of ICT. Beyond this impact, leaders are the key to interaction among the other fractals of ICT underway while the group develops.

Figure 2 summarizes the ICT model in group development. It also reviews the core stages proposed by other theories.

insert Figure 2 about here

\section{Group Development Through ICT}

\section{Discovery \#1: Emergence of Shared Ideal, Vision, or Dream}

The emergence and exploration of an "ideal self" is seen as the motivational force behind intentional change, composed mainly by three core features, namely hope, an image of a desired future, and core identity (Boyatzis \& Akrivou, earlier in this issue). The equivalent of the ideal self at a group level is an image of the ideal or a shared vision, with the same three underlying elements. These are all critical for subsequent group development. In initial phases of any group, there is little reason to believe that a vision will become true or that a shared ideal will come to fruition (Gersick, 1991; Kuhn, 1970; Tushman et al., 1985). Therefore emergence of hope, dreams, possibilities, as well as the intentional attention to the processes which create and strengthen a core group identity are critical from the very first iteration of group ICT. 
In the initial iteration of ICT, this shared ideal takes the form of generative conversation and inquiry of "what is our purpose and vision as a group". This conversation at the very beginning of a group's life is fundamental for subsequent development. The shared cognition around an ideal or purpose generates a source of positive emotion, guiding the group process, thereafter, as its Positive Emotional Attractor. In subsequent iterations of ICT the shared ideal or vision is further developed and refined, in a way which protects from groupthink (Janis, 1982). As a result of emerging salience, consciousness and coherence about this shared ideal within and outside the group boundaries, deep positive emotion and the PEA become the anchor of the group's subsequent development. Although in ICT, the role of negative emotional attractor (NEA) is seen as functional to change, the PEA becomes the emotional anchor, which balances any disturbances, shocks and feelings of group helplessness, emerging from the experience of the NEA.

In various iterations of ICT, group members can share and explore their own ideal self in increasing depth. In our model, the early formation of the group's ideal identity and purpose facilitates the individual members exploring their own ideal self. When prematurely pressing towards convergence, arousal of the NEA could take over and provoke a downward spiral, inhibiting development. This will appear as a form of groupthink, with pressures toward compliance exerted on any minority group members, as well as suppressing creativity and flexibility.

\section{Discovery \#2: Exploration of Norms, Paradoxes, Challenges, and Gaps}

This phase serves as a reality check in the group and creates the tension, experienced as the gaps or threats to the accomplishment of the shared ideal. In initial iterations of ICT, it can be experienced as individual disappointment in the group not being consistent with the vision. Or, it can be related to inability to solve some of the classic paradoxes of group life, 
like the democracy-authority paradox, the leader-member paradox, or the trust-distrust paradox (Smith \& Berg, 1987).

This phase allows the strongest experience of emotional bi-polarity and the resulting dynamic tension. When the experience or the image of the ideal is salient, alternating activation of both positive and negative emotions create a dynamic balance field, which pulses the mood of the group towards action to eliminate tension.

As explained in detail by Howard (earlier in this issue), during arousal of the PEA, restorative effects of positive emotions enable the group to use cognitive flexibility, group self-affirmation, resilience and recovery from negative affect and thought. This allows the group to return to the positive emotional PEAS and bounce away from the NEA.

\section{Discovery \#3: The Group's Learning Agenda}

In Discovery \#3, the group develops a learning agenda that focuses commitment to change goals and action steps. During various iterations of ICT the group may decide to implicitly deal with some of these issues, rather than bring them out "on the table". Some effective groups may be able to deal with paradoxes and gaps implicitly rather than explicitly at times. That is, their development may proceed without having to pass through a "storming" phase (Murninghan et al., 1991). During later iterations of ICT, the group becomes time conscious. This time anxiety may push the group towards the Negative Emotional Attractor and facilitate development.

\section{Discovery \#4: Group Experimentation and Practice}

In Discovery \#4, the group is involved in experimentation and practice with new behavior or norms, consistent with their learning agenda. During experimentation and practice, the PEA plays a critical role in sustaining curiosity and mindfulness, optimism and group efficacy, about the novel way for them to function. This has to be a shared mood. Due to the contagion of emotion in such 
groups, when a few of the members feel it and express it, then others catch it. This pattern of triual and exploration of new ways of acting and functioning and the associated positive mood from the PEA creates a self-sustaining movement toward the shared vision.

\section{Discovery \#5: Resonant Relationships}

During initial iterations of ICT, people in the group focus on establishing and subsequently maintaining of trusting, supportive relationships. These can be best described as "resonant relationships" within the group members (Goleman, Boyatzis, and McKee, 2002; Boyatzis and McKee, 2005). In subsequent iterations of ICT, the group can focus attention and build resonant relationships outside its membership. Again, the leader often plays the central role in initiating such relationships (Druskat and Wheeler, in press). Resonant intergroup relationships are critical for both the establishment of the group's core identity within its larger environment. It helps with differentiation. Resonant relationships with other groups also helps in establishing facilitating mechanisms, such as building social capital, or exchanging feedback with its environment. These help the group move towards its vision in a more grounded and mature way. During this phase, the PEA triggers positive ideation and feeling (i.e., cognitions that are emotionally centering (Howard, see article earlier in this issue)). The NEA creates the tensions and reflection, through experiences of still existing ingroup vs. out-group boundaries and challenges to further developing these critical relationships.

\section{Implications for Future Research and Practice}

Increasingly, scholars in the small group field are raising a discourse related to treating small groups as complex systems (Arrow et al. 2000, 2005; McGrath \& Tschan, 
2004a, 2004b). This article is attempted to build this discourse. We offered two different theoretical contributions.

First, we reviewed existing literature of group development and identified areas of convergence as well as gaps that present challenges for the development of new theoretical models. Mainly, we highlighted four areas which are not sufficiently addressed by existing models of group development: (1) the complex and discontinuous nature of change in groups; (2) the role of intentionality in group development process; (3) the role of ideals, or shared vision, hopes and dreams at the group level as the drivers of change; and (4) the need to move away from seeing negative emotion as fundamentally linked to change and development processes in groups, and the need to develop models that examine the role of positive emotion in the group development process.

Secondly, we introduced a new theoretical framework for group development. We proposed ICT as a spiral iterative process of group development and discussed its main theoretical features, the processes involved in how ICT applies in groups over time, as well as its main discontinuities that lead to group transformation.

There is a need and a call in parts of the academic community to study phenomena of change in a more complex form. Many models in management and organizational science are static. Many models treat change as a systematic process following the rules of evolutionary biology. Other existing models are still heavily influenced by the psychoanalytic traditions of the last century, related to trauma, conflict and negative emotion.

Testing the model and its propositions offered here can help move small group development insight to a new level. This would help the scholars as well as the many practitioners who teach and use small group techniques in their educational programs, human, organization, community, and country development efforts. 


\section{References}

Andriani, P. \& McKelvey, B. (2005), Power Law Phenomena in Organizations: Redirecting Organizational Studies, Unpublished manuscript, Durham Business School, Durham, UK.

Arrow, H., McGrath, J. E., \& Berdahl, J. L. (2000), Small groups as complex systems: Formation, coordination, development and adaptation, Sage Publications, Thousand Oaks, California

Arrow, H., Henry, K. B., Poole, M. S., Wheelan, S., Moreland, R., (2005), “Traces, Trajectories and Timing: The temporal perspectives on groups", In Poole, M. S., \& Hollingshead, A. B. (eds.): Theories of Small Groups. Sage Publications, Thousand Oaks, California, pp. 313-369

Aspinwall, L.G. \& Staudinger, U.M. (Eds.), (2003), “A Psychology of Human Strengths: Fundamental Questions and future directions for a positive psychology", American Psychological Association, Washington, DC.

Bach, G. R. (1954), Intensive group psychotherapy, Ronald Press, New York, pp. 268-293

Bales, R. F. (1950), Interaction Process Analysis : A method for the study of small groups. Addison-Wesley, Cambridge, Mass.

Bales, R. F. (1953), "The equilibrium process in small groups", In T. Parson, R. F. Bales, \& E. A. Shils, Working papers in the theory of action, Free Press, Glencoe, Ill, pp. 111161

Bales, R. F., Mills, T. M., Roseborough, M., \& Strodtbeck, F. L (1951), “Channels of communication in small groups", American Sociological Review, Vol. 16, pp. 461468

Bales, R.F., \& Strodbeck, F.L. (1951), "Phases in group problem solving” Journal of Abnormal and Social Psychology, Vol. 46, pp. 485-495 
Bennis, W. G., \& Shepard, H. A. (1956), “A theory of group development”, Human Relations, Vol. 9, pp. 415-437

Bion, W. R. (1961), Experiences in Groups, Basic Books, New York

Book, L. (1999), “Towards a theory of reflexive intentional systems”, Synthese, Vol. 118, pp. $105-117$

Boyatzis, R. E., (in press), “ Intentional Change from a Complexity perspective. “. Journal of Management Development

Boyatzis, R.E., (2001), “Developing emotional intelligence”. In C. Cherniss, R.E. and D. Goleman (eds.), The emotionally intelligent workplace, Jossey-Bass, San Francisco, pp. XX (Richard)

Boyatzis, R.E., and Akrivou K. (in press), "The Ideal Self as the driver of intentional Change", Journal of Management Development

Boyatzis, R. E., and McKee A. (2005). Resonant Leadership: Renewing Yourself and Connecting with Others Through Mindfulness, Hope, and Compassion, Harvard Business School Press, Boston

Cacioppo, J. t., \& Berntson, G., G., (1999). The Affect System: Architecture and Operating Characteristics, Current Directions in Psychological Science, American Psychological Society, Washington DC

Cameron, K.S., Dutton, J. E., \& Quinn, R. E. (Eds.), (2003), Positive Organizational Scholarship: Foundations of a new Discipline, Berrett-Koehler Publishers, Inc., San Francisco

Chang, E. C. (ed.). (2001), Optimism and pessimism: Theory, research and practice, American Psychological Association, Washington, DC 
Chang, A., Bordia, P., Duck, J.(2003), "Punctuated Equilibrium and Linear Progression: Toward a New Understanding of Group Development", Academy of Management Journal, Vol. 46, No 1, pp. 106-118

Deutsch, M. (1971), “Towards an understanding of conflict” International Journal of Group Tensions, Vol.1, pp. 42-54

Diamond, L. \& Aspinwall, L (2003), "Emotion regulation across the life span: an integrative perspective emphasizing self-regulation, positive affect and dyadic processes”. Motivation and Emotion, Vol. 27, no 2, pp.125-156

Fredrickson, B. L. (2001), ”The Role of Positive Emotions in Positive Psychology: The broaden-and-build theory of positive emotions". American Psychologist, Vol. 56, no 3, pp.218-226

Fredrickson, B. L., Mancuso, R. A., Branigan, C., \& Tugade, M. M. (2000), “The undoing effects of positive emotions", Motivation and Emotion, Vol. 24, No 4, pp.237-258.

Fredrickson, B. L., Soiner, T. (2002), "Positive emotions trigger upward spirals toward emotional well being”, Psychological Science, Vol.13, pp.162-175

Freud, S. (1936), The problem of anxiety. Trans. By H. A. Bunker, Psychoanalytic Quarterly Press and Norton, New York.

Freud, S. (1959), Group Psychology and the analysis of the ego. Trans. By J. Strachey. (original eds, 1922, International Psychoanalytic Press, London), Liveright, New York

Gersick, C. J. (1991), "Revolutionary change theories: A multilevel exploration of the punctuated equilibrium paradigm", Academy of Management Review, Vol.16, pp. 274-309

Gersick, C. J. (1989), „Marking Time: Predictable Transitions in Task Groups”, Academy of Management Journal, Vol. 32, pp. 274-308 
Gersick, C. J. (1988), “Time and transition in work teams: Toward a new model of group development", Academy of Management Journal, Vol. 31, pp. 1-41

Gibbard, G., \& Hartman, J. (1973), "The Oedipal paradigm in group development: a clinical and empirical study", Small Group Behaviour, Vol. 4, No 3, pp.305-354.

Gibbard, G., Hartman J., Mann, R. (1974), Analysis of groups; contributions to theory, research and practice, Jossey-Bass Publishers, San Francisco

Goldie, P. (2002), "Emotions, feelings and intentionality”, Phenomenology of the Cognitive Sciences, Vol. 1, pp. 234-254.

Hartman, J. (1969), The role of ego state distress in the development of self-analytic groups, Unpublished Doctoral Dissertation, AAT 7021687, source DAI-B 31/05 University of Michigan, Michigan, p. 2986

Hogg, M. A \& Tindale, S. (2003), (eds.), Group Processes, Blackwell Publishers, Ltd, Malden, MA

Howard, A. (in press), "The role of positive and negative emotional attractors in intentional Change”, Journal of Management Development

Janis, I. L. (1982), Groupthink, Houghton Mifflin, Boston

Mann, R. (1966), “The development of member and member-trainer relationships in selfanalytic groups", Human Relations, Vol.19, No 1, pp.85-115.

Mann, R., Gibbard, G., \& Hartman, J. (1967), Interpersonal styles and group development: an analysis of the member-leader relationship, Wiley, New York

Manson, P. (1993), "What is a group: A Multilevel Analysis", Advances in Group Processes, $10,253-281$.

McGrath, J. E., \& Tschan, F. (2004a), “Dynamics in groups and teams: Groups as complex action systems", In M. S. Poole \& A H. Van de Ven (Eds.), Handbook of 
organisational change and development, Oxford University Press, Oxford, UK, pp. $50-72$

McGrath, J. E., \& Tschan, F. (2004b), Temporal matters in social psychology: Examining the role of time in the lives of groups and individuals, American Psychological Association, Washington, DC, USA

McLeod, P. L., \& Kettner-Polley, R., (2005), “Psychodynamic perspectives on small groups" In Poole, M. S., \& Hollingshead, A. B. (eds.): Theories of Small Groups. Sage Publications, Thousand Oaks, California, pp.63-99

Miles, M. B. (1953), "Human relations training: how a group grows", Teachers College Record, Vol.55, pp. 90-96

Mills, T. (1964), Group Transformations: An analysis of a learning group, Prentice Hall, Englewood Cliffs, NJ

Murnighan, J. K., \& Conlon, D. E. (1991), “The Dynamics of Intense Work Groups: A Study of British String Quartets”, Administrative Science Quarterly, Vol.36, pp. 165-186.

Oettingen, G. (1996), "Positive fantasies and motivation", In P. M. Gollwitzer \& J. A. Bargh (Eds.), The psychology of action: Linking cognition and motivation to behavior, Guilford, pp. 236-259

Scheier, M.F., \& Carver, C.S. (1987), "Dispositional optimism and physical well-being: The influence of generalized outcome expectancies", Journal of Personality, Vol.55, pp. $169-210$

Schutz, W. C. (1958), FIRO: A three dimensional theory of interpersonal behaviour, Rinehart, New York, pp.168-188.

Seligman, M. E. P. (1991), Learned optimism, Knopf, New York

Skinner, E. A.,(1996)," A guide to constructs of control”, Journal of Personality and Social Psychology, Vol. 71, pp. 549-570. 
Smith, K. K., \& Berg, D. N. (1987), Paradoxes of Group Life, Jossey-Bass. John Willey \& Sons, Inc., New York

Snyder, C.R., (2002), "Hope Theory: Rainbows in the Mind”, Psychological Inquiry, Vol.13, No 4, pp. 249-275

Snyder, C. R. (1996), "To hope, to lose and hope again", Journal of Personal and Interpersonal Loss, Vol. 1, pp. 3-16.

Snyder, C. R. (1994), "The psychology of hope: You can get there from here", Free Press, New York

Snyder, C. R., Feldman, D.B., Taylor, S.D., Schroeder, L.L., Adams, V.H.(2000,a), “The roles of hopeful thinking in preventing problems and enhancing strengths", Applied and Preventive Psychology, Vol. 15, Pp. 262-295

Snyder, C.R., Ilardi, S.S., Cheavens Jl, Michael, S.T., Yamhure, L., Sympson, S.(2000,b),'The role of hope in cognitive behavior therapies", Cognitive Therapy and Research, Vol. 24, pp. 747-762.

Snyder, C. R., Ilardi, S., Michael, S.E., Cheavens, J.(2000, c), “Hope theory: Updating a common process for psychological change”, In C. R. Snyder \& R. E. Ingram (Eds.), Handbook of Psychological Change: Psychotherapy processes and practices for the $21^{\text {st }}$ century, New York: Wiley, pp. 128-153

Snyder, C.R., McCullough, M.E. (2000,d), “A positive psychology field of dreams : « If you build it, they will come... “, Journal of Social and Clinical Psychology, Vol. 19, pp.151-160.

Stotland, E. (1969), The psychology of hope. San Franciscio: Jossey-Bass, San Francisco Taylor, S. E., Pham, L.B., Rivkin, I.D., Armor, D.A.(1998), “ Harnessing the imagination : Mental Simulation", American Psychologist, Vol.53, pp. 429-439 
Tuckman, B. W. (1965), “Developmental sequence in small groups”, Psychological Bulletin, Vol. 63, No 6, pp.384-399.

Tuckman, B. W., \& Jensen, M. A.C., (1977), "Stages in small group development revisited”, Group and Organizational Studies, Vol. 2, pp. 419-427.

Wheelan, S. A., \& McKeage, R. L. (1993), “Developmental Patterns in Small and Large Groups”, Small Group Research, Vol. 24, No 1, pp, 60-83. 
Figure 1. ICT Multiple Iterations Over Time in Groups

Group Identity

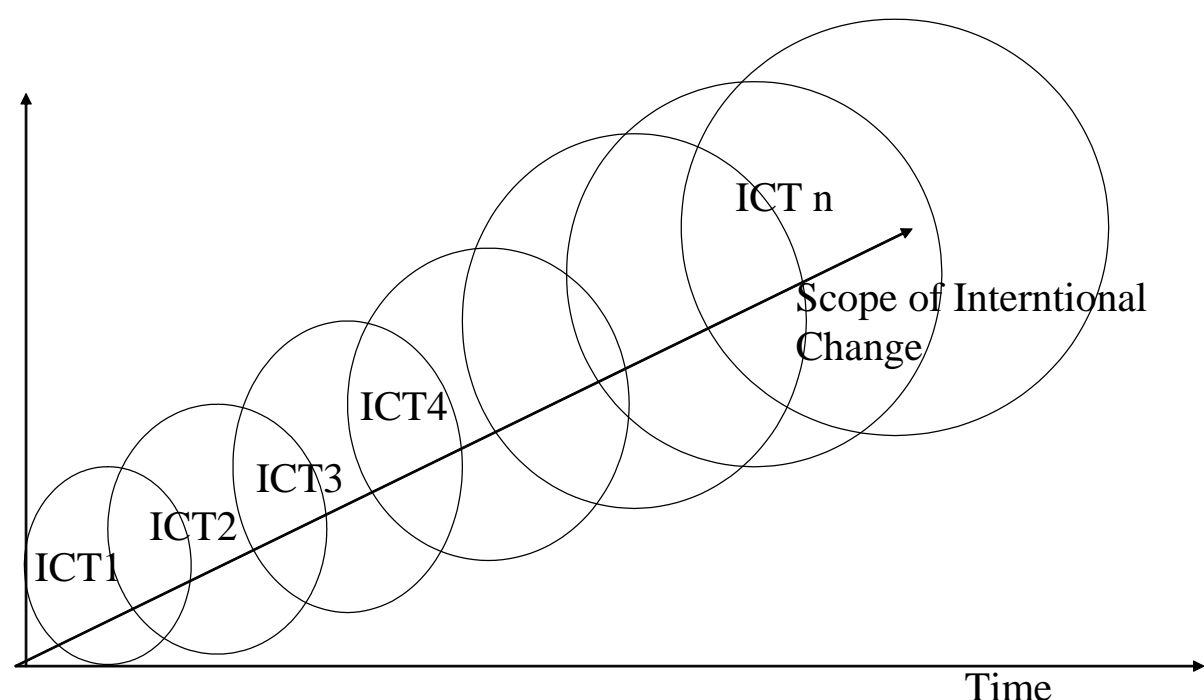


Figure 2. Team Intentional Change Comparison of Models and Theories

ICT

Discovery

Cycle I

\#1 Ideal Self: Dependence-

Identity,

Purpose,

Shared Values,

Shared Vision

\#2 Real Self:

Norms

Counter-

dependence

Enchantment

Consensua

validation

Negotiating

Agenda:

Goals, Tasks

\#4 Exper \&

Practice:

Exploration

Of new norms

\#5 Res. Rel's

Resolution

Consensual

Validation

Recycle

Separation

Consensual

Production

Recycle
Bion

Shutz

Tuckman

Dependency

Inclusion

Forming

Fight/Flight

Control

Norming \&

Storming

Storming

Fight/Flight

Performing

Pairing

Affection

Recycle

Recycle 
Figure 2. Team Intentional Change Comparison of Models and Theories continued

ICT

Discovery

\#1 Ideal Self:

Identity,

Purpose,

Shared Values,

Shared Vision

\#2 Real Self:

Norms

\#3 Learning

Agenda:

Goals, Tasks

\#4 Exper \&

Practice:

Exploration

Of new norms

\#5 Res. Rel's

Recycle

Recycle Recycle

Vs.
Gersick

Hackman

Task definition \&

focus

task of group focus

task group

metaphor

$\begin{array}{lll}\text { Coalitional } & \begin{array}{l}\text { Emergence } \\ \text { shaping; }\end{array} & \begin{array}{l}\text { Working through } \\ \text { of UPF \& }\end{array}\end{array}$

UNB

anxiety

Assimilation

New boundary, UNB conflict

establish

solidarity \&

Cohesiveness

change in initial

conditions \& new

perspective \& redef

Of their work just before deadline:

Task/mission

completion focus

$\begin{array}{lll}\text { UNB moves } & \text { Personal } & \text { just before deadline: } \\ \text { D } & \text { mutual } & \text { Task/mission } \\ & \text { exploration } & \text { completion focus }\end{array}$

then $\mathrm{P}$, then $\mathrm{F} \quad$ Mutual

synthesis

Termination,

Separation 